Journal for ImmunoTherapy of Cancer

\title{
Understanding $T$ cell phenotype for the design of effective chimeric antigen receptor $T$ cell therapies
}

Daniela GM Tantalo, ${ }^{1}$ Amanda J Oliver, ${ }^{1,2}$ Bianca von Scheidt, ${ }^{1}$ Aaron J Harrison, ${ }^{1}$ Scott N Mueller, ${ }^{3,4}$ Michael H Kershaw, ${ }^{1,2}$ Clare Y Slaney (i] ${ }^{1,2}$

To cite: Tantalo DGM, Oliver AJ, von Scheidt B, et al. Understanding T cell phenotype for the design of effective chimeric antigen receptor $T$ cell therapies. Journal for ImmunoTherapy of Cancer 2021;9:e002555. doi:10.1136/ jitc-2021-002555

Accepted 20 April 2021
Check for updates

(c) Author(s) (or their employer(s)) 2021. Re-use permitted under CC BY-NC. No commercial re-use. See rights and permissions. Published by BMJ.

${ }^{1}$ Research, Peter MacCallum Cancer Centre, Melbourne, Victoria, Australia

${ }^{2}$ Sir Peter MacCallum Department of Oncology, University of Melbourne, Parkville, Victoria, Australia ${ }^{3}$ Department of Microbiology and Immunology, The Peter Doherty Institute for Infection and Immunity, Melbourne, Victoria, Australia

${ }^{4}$ The Australian Research Council Centre of Excellence in Advanced Molecular Imaging, The University of Melbourne, Melbourne, Victoria, Australia

Correspondence to Dr Clare Y Slaney; clare.slaney@petermac.org

Dr Michael H Kershaw; michael.kershaw@petermac.org

\section{ABSTRACT}

Rapid advances in immunotherapy have identified adoptive cell transfer as one of the most promising approaches for the treatment of cancers. Large numbers of cancer reactive T lymphocytes can be generated ex vivo from patient blood by genetic modification to express chimeric antigen receptors (CAR) specific for tumor-associated antigens. CAR T cells can respond strongly against cancer cells, and adoptive transferred CAR T cells can induce dramatic responses against certain types of cancers. The ability of $T$ cells to respond against disease depends on their ability to localize to sites, persist and exert functions, often in an immunosuppressive microenvironment, and these abilities are reflected in their phenotypes. There is currently intense interest in generating CAR T cells possessing the ideal phenotypes to confer optimal antitumor activity. In this article, we review $\mathrm{T}$ cell phenotypes for trafficking, persistence and function, and discuss how culture conditions and genetic makeups can be manipulated to achieve the ideal phenotypes for antitumor activities.

\section{INTRODUCTION}

Chimeric antigen receptor (CAR) T cell adoptive transfer has shown great promise and is currently approved by multiple countries in treating some hematological malignancies. ${ }^{1}$ In this therapy, $\mathrm{T}$ cells from patients with cancer are genetically modified to express CARs specific for cancer antigens. CARs are synthetic receptors that usually comprise an extracellular domain specific for a tumor antigen, a cytoplasmic domain containing activation and costimulatory molecules (such as $\mathrm{CD} 3 \mathrm{e}, \mathrm{CD} 28$, and $4-1 \mathrm{BB}$ ), and a hinge region that links the two domains. However, applying CAR T cell therapies to solid tumors has been hampered by additional challenges including limited infiltration and persistence of CAR T cells in the tumors, and a hostile immunosuppressive tumor microenvironment (TME) ${ }^{2-4}$

Gene expression profiles and cell phenotypes determine if $\mathrm{T}$ cells can successfully traffic, persist and function in the tumor. Here, we discuss the progressive change in phenotypes of $\mathrm{T}$ cells during the course of a natural $\mathrm{T}$ cell response as well as investigate studies that have attempted to emulate these phenotypes in CAR T cells, providing a rationale for the optimum CAR T cell phenotypes to achieve enhanced efficacy. We propose three central characteristics to be considered when designing cellular therapies: the ability to self-renew and persist, the ability to traffic to and penetrate disease sites, and the ability to function while resisting exhaustion induced by an immunosuppressive TME. These three characteristics can be revealed as phenotypes that specify markers for $\mathrm{T}$ cell differentiation, trafficking and exhaustion respectively. Herein, we discuss the relevance of these phenotypes in providing a rationale for the optimum design of CAR T cell therapy for cancers with a focus on solid tumors.

\section{SELF-RENEWAL AND PERSISTENCE: T CELL DIFFERENTIATION PHENOTYPES Naïve, memory and effector $T$ cells}

A resting naïve $T$ cell $\left(\mathrm{T}_{\mathrm{N}}\right)$ that circulates and traffics through the lymphoid tissues remains uncommitted to its effector and memory fates until receiving signals from antigenpresenting cells (APCs) alongside signaling downstream of their cytokine receptors. In response to the specific cytokine stimulation, the activated $\mathrm{T}$ cells will differentiate into a variety of phenotypes that together enable an effective immune response and establishment of immunological memory. ${ }^{56}$

The conventional model of $\mathrm{T}$ cell differentiation proposes that $\mathrm{T}_{\mathrm{N}}$ cells can differentiate into effector $\mathrm{T}$ cells $\left(\mathrm{T}_{\mathrm{FFF}}\right)$, specialized killer cells that produce cytotoxic molecules and effector cytokines. Most of the $\mathrm{T}_{\mathrm{EFF}}$ cells die during an immune response, but some of them survive and differentiate into memory $\mathrm{T}$ cells that are capable of mounting a memory response to a subsequent encounter of their 


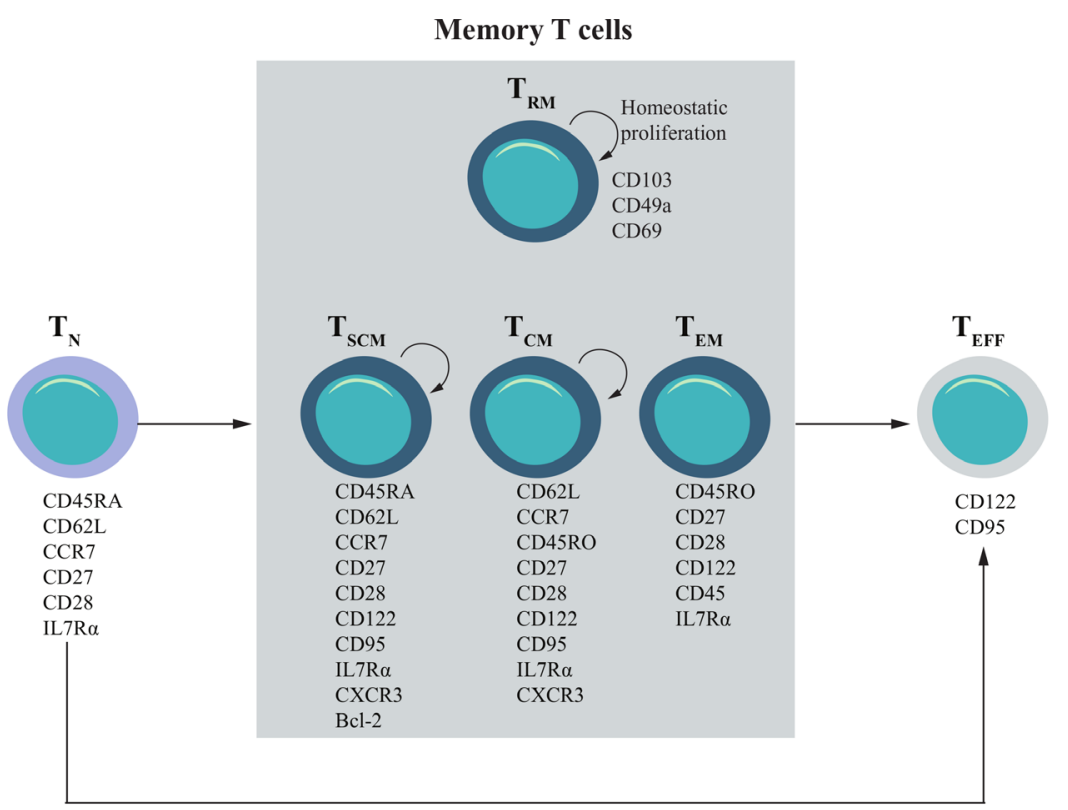

\section{Self-renewal Proliferative capability Multipotency}

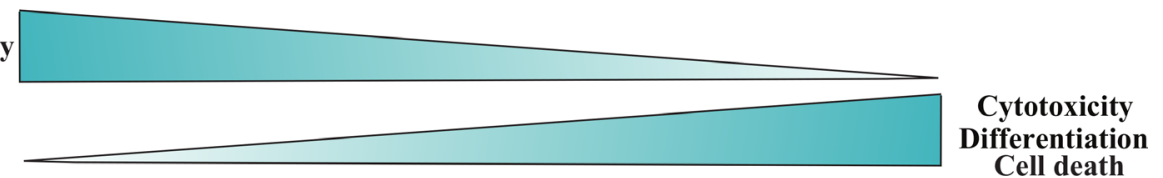

Figure 1 Phenotype definition and characteristics of T cell differentiation states. A widely accepted model of T cell differentiation in adoptive $T$ cell transfer field dictates that T cells progress along a linear trajectory of development, with each differentiation phase displaying a unique phenotype with altered functionality and properties. This model proposes while some primed naïve $T$ cell $\left(T_{N}\right)$ cells will differentiate into effector $T$ cells $\left(T_{E F F}\right)$, some primed $T_{N}$ cells will differentiate into memory $T$ cells, including stem memory $T$ cells $\left(T_{S c M}\right)$, a subtype categorized by their ability to self-renew, while also possessing multipotent differentiation capacity, central memory $T_{\text {cells }}\left(\mathrm{T}_{\mathrm{CM}}\right.$, long-lived), effector memory $\mathrm{T}_{\text {cells }}\left(\mathrm{T}_{\mathrm{EM}}\right)$, and tissue residential memory $T$ cells $\left(T_{R M}\right)$. These memory $T$ cells can both self-renew, and give rise to a pool of $\mathrm{T}_{\mathrm{EFF}}$ Bcl 2, B-cell lymphoma 2; IL7R $\alpha$, interleukin receptors.

TCR-specific antigens. Although this conventional model has been widely accepted and predicts that $\mathrm{T}_{\mathrm{EFF}}$ cells can give rise to memory $\mathrm{T}$ cells, it has also been debated that $\mathrm{T}_{\mathrm{EFF}}$ cells are terminally differentiated and do not give rise to memory cells. Instead, it was proposed that a proportion of memory cells are differentiated from the activated $\mathrm{T}_{\mathrm{N}}$ cells that never experience a full-strength effector state. ${ }^{7}$ In fact, a number of $\mathrm{T}$ cell differentiation models have been proposed. ${ }^{7-9}$ In this review, we have adopted the nomenclatures that are widely used in the field of adoptive $\mathrm{T}$ cell transfer (ACT) in figure 1.

The $\mathrm{T}_{\mathrm{FFF}}$ phenotype was originally considered ideal for ACT therapies due to their potent killing capacity. However, $\mathrm{T}_{\mathrm{FFF}}$ cells have a poor ability to expand and persist in vivo. Transcriptome analysis has identified that a less differentiated $\mathrm{T}$ cell signature is associated with superior anti-cancer activity. Fraietta $e t a l^{10}$ studied 41 chronic lymphocytic leukemia patients treated with CD19-CAR, and found that a good response was associated with $\mathrm{CD}_{2} 7^{+} \mathrm{CD} 45 \mathrm{RO}^{-} \mathrm{CD} 8^{+}$cell population at the time of leukapheresis. This phenotype is consistent with a resting antigen-experienced cell with long-lived memory characteristics. ${ }^{11}$ This study links clinical responses to $\mathrm{T}$ cell differentiation status. Consequently, the CAR T cell field is moving towards designing protocols to retain less differentiated $\mathrm{T}$ cells.

Initially, efforts were focused on generating $\mathrm{T}$ cell products with $\mathrm{T}_{\mathrm{CM}}\left(\mathrm{CD} 62 \mathrm{~L}^{+} \mathrm{CCR} 7^{+}\right)$and $\mathrm{T}_{\mathrm{EM}}$ (CD62LCCR7 $\left.7^{-}\right)$ cell phenotypes. Naturally occurring $\mathrm{T}_{\mathrm{CM}}$ cells express the lymph node homing molecules CD62L and CCR7 and are considered to have enhanced replicative capacity but limited effector functions. $\mathrm{T}_{\mathrm{EM}}$ cells are more cytolytic and express chemokine receptors and adhesion molecules necessary for trafficking to peripheral tissues, rather than lymph nodes. $\mathrm{T}_{\mathrm{FM}}$ cells will terminally differentiate after a limited number of divisions, although some can convert to $\mathrm{T}_{\mathrm{CM}} \cdot{ }^{12}$ Klebanoff $e$ e $a l^{13}$ demonstrated that $\mathrm{T}$ cells generated in vitro with a $\mathrm{CD} 62 \mathrm{~L}^{+} \mathrm{CCR} 7^{+}$phenotype $\left(\mathrm{T}_{\mathrm{CM}}\right.$-like) have a lower expression of genes associated with effector functions than the CD62LCCR 7 cells $\left(\mathrm{T}_{\mathrm{FM}^{-}}{ }^{-}\right.$ like), predicting a less differentiated status. Importantly, the $T_{C M}$-like cells had a preference to traffic to secondary lymphoid tissues, which resulted in enhanced clearance of tumors in the mice. ${ }^{13}$ These findings exemplified the benefit of a low differentiation T cell status on ACT efficacy. Clinical protocols have been established for generating CAR $T$ cell products with enriched memory-like $T$ cells. For example, an early study transduced the enriched 
$\mathrm{CD}^{+} \mathrm{CD} 45 \mathrm{RA}^{-} \mathrm{CD} 62 \mathrm{~L}^{+} \mathrm{T}_{\mathrm{CM}}$ cells from human peripheral blood mononuclear cells using lentiviral vectors encoding a CD19-CAR. ${ }^{14}$ These $\mathrm{T}_{\mathrm{CM}}$-CAR $\mathrm{T}$ cells retained their $\mathrm{T}_{\mathrm{CM}^{-}}$ like phenotype $\left(\mathrm{CD} 62 \mathrm{~L}^{+}, \mathrm{CD} 28^{+}\right)$after expansion and demonstrated CD19-CAR mediated antitumor effect in vitro. Importantly, when adoptively transferred to NSG mice, these $\mathrm{T}_{\mathrm{CM}}$-like CAR $\mathrm{T}$ cells were capable of human interleukin (IL)-15-dependent homeostatic engraftment. Subsequently, the safety and feasibility using these $\mathrm{T}_{\mathrm{CY}} \mathrm{C}^{-}$ like CAR T cells were demonstrated in a phase I trials. ${ }^{5}$ Throughout this review, we refer to in vitro generated $\mathrm{T}$ cells with memory phenotypes as $\mathrm{T}$ memory-like cells.

\section{Stem-like memory T cells}

Recently, the stem-like memory $\mathrm{T}$ cells $\left(\mathrm{T}_{\mathrm{SCM}}\right)$-like cells are considered a preferred phenotype for $\mathrm{CAR} \mathrm{T}$ cell products because of their self-renewal capacity, ability to generate other $\mathrm{T}$ cell subsets and their increased ability to engraft. ${ }^{16}{ }^{17} \mathrm{~T}_{\mathrm{SCM}}$ cells are a T memory cell subtype categorized by their ability to self-renew while possessing multipotent differentiation capacity. $\mathrm{T}_{\mathrm{SCM}}$ cells can give rise to long-lived $\mathrm{T}_{\mathrm{CM}}, \mathrm{T}_{\mathrm{EM}}$, and a pool of short-lived $\mathrm{T}_{\mathrm{EFF}} . \mathrm{T}_{\mathrm{SCM}}$ cells have stem-like properties and are phenotypically similar to $\mathrm{T}_{\mathrm{N}}$ cells. Both subsets express CD45RA, CD62L, CCR7, CD27 and CD28, but diverge in their expression of CD122 and CD95, markers which demarcate antigenexperienced memory subsets (figure 1). ${ }^{16}$

The investigation of $\mathrm{T}_{\mathrm{SCM}}$ cells has been difficult, due to the paucity of the $\mathrm{T}_{\mathrm{SCM}}$ cells in the body, with only $2 \%-3 \%$ of circulating $\mathrm{T}$ cells in humans having the $\mathrm{T}_{\mathrm{SCM}}$ cell phenotype. $\mathrm{T}_{\mathrm{SCM}}$ cells were first described in mice, where a $\mathrm{T}$ cell subset with the naïve phenotype of $\mathrm{CD} 44^{\mathrm{lo}} \mathrm{CD} 62 \mathrm{~L}^{\mathrm{hi}}$ also expressed memory markers such as CD122, B-cell lymphoma 2 (Bcl-2), as well as stem cell antigen-1 (Sca1). ${ }^{18}$ Sca-1 does not have a human ortholog, but Gattinoni et $a l^{16}$ described the generation of human $\mathrm{T}_{\mathrm{SCM}}$-like cells by inducing Wnt signaling in $\mathrm{T}$ cells in vitro. Inhibition of this pathway with TWS119, a Wnt pathway activator, promoted the expression of TCF1 and LEF1, which have been determined to promote $\mathrm{T}$ cell persistence and self-renewal capacity. ${ }^{19}$ The resulting $\mathrm{T}_{\mathrm{SCM}}$-like cells retained a $\mathrm{CD} 45 \mathrm{RO}^{-} \mathrm{CD} 62 \mathrm{~L}^{+}$naive-like phenotype but expressed high levels of memory markers including CD95 and CD122. In addition, these $\mathrm{T}_{\mathrm{SCM}}$-like cells expressed all the core phenotype markers including CD122, Bcl-2 and CXCR3, ${ }^{20}$ similar to the murine $\mathrm{T}_{\mathrm{SCM}}$ cells described previously. ${ }^{18}$

Direct evidence that a $\mathrm{T}_{\mathrm{SCM}}$-like phenotype is desirable for CAR T cell products comes from a clinical trial where CD19-CAR T cells were adoptively transferred to patients with B-cell malignancies. In this study, the CD19-CAR T cell in vivo expansion correlated with the frequency of a $\mathrm{T}_{\mathrm{SCM}}$-like phenotype within the infused product. ${ }^{21}$ In addition to the superior proliferative capacity, ${ }^{16}$ the tropism of $\mathrm{T}_{\mathrm{SCM}}$-like cells may also contribute to their enhanced engraftment. It was demonstrated that naturally occurring $\mathrm{T}_{\mathrm{SCM}}$ cells in non-human primates have tropism for lymphoid organs, where they receive survival signals. ${ }^{22}$
Although further studies are needed to confirm the tropism of the $\mathrm{T}_{\mathrm{SCM}}$-like cells in ACT settings, their phenotype including the expression of CD62L and CCR7, indicates that $\mathrm{T}_{\mathrm{SCM}}$-like cells may have a preference to traffic to lymphoid tissues. The resistance to apoptosis may also contribute to better engraftment. High expression of anti-apoptotic markers, such as BCL-2, is a common feature of $\mathrm{T}_{\mathrm{SCM}}$-like cells. ${ }^{16}$ In fact, adoptively transferred $\mathrm{T}_{\mathrm{SCM}}$-like cells were observed to persist while maintaining precursor potential in the patients of severe combined immunodeficiency disease for up to 12 years. ${ }^{23}$

To date, a number of strategies have been developed to generate $\mathrm{T}_{\mathrm{SCM}}$-like CAR $\mathrm{T}$ cells for adoptive transfer. Early investigation demonstrated that Wnt signaling promotes the generation of $\mathrm{T}_{\mathrm{SCM}}$-like cells in vitro. ${ }^{20}$ Subsequently, a clinical-grade platform using TWS119 was established to produce CD19-CAR $\mathrm{T}_{\mathrm{SCM}}{ }^{24}$ These CD19-CAR $\mathrm{T}_{\mathrm{SCM}}$ cells exhibited enhanced metabolic fitness compared with CAR T cells cultured using a protocol without Wnt signaling induction. Controversially, a number of studies have demonstrated that $\beta$-catenin accumulation in $\mathrm{T}$ cells, an effect induced by TWS119, leads to reduced T cell expansion and impaired $\mathrm{T}$ cell effector function, which could potentially damage T cell-mediated immunity. ${ }^{25} 26$

Subsequently, IL-7 and IL-15 were successfully used to generate $T_{S C M}$-like cells from $T_{N}$ cells and demonstrated more efficiency in expanding and sustaining $\mathrm{T}_{\mathrm{SCM}}$-like cells than TWS119. ${ }^{17}$ IL-7 was shown to be critical for the $\mathrm{T}_{\mathrm{SCM}}$-like cells to preserve a CD45RA ${ }^{+} \mathrm{CD}_{62 \mathrm{~L}^{+}}$phenotype, while IL-15 or IL-2 supported cell expansion, with IL-15 providing superior $\mathrm{T}_{\mathrm{SCM}}$ phenotype preservation compared with IL-2(17). In a separate study, it was demonstrated that the frequency of the $\mathrm{CD} 45 \mathrm{RA} \mathrm{C}^{+} \mathrm{CCR} 7^{+}$ $\mathrm{T}_{\mathrm{SCM}}$ cell-like phenotype generated using $\gamma$-cytokines in the CAR T cell product correlated with expansion and persistence of CD19-CAR T cells in patients. ${ }^{21}$ Currently, the efficacy of IL-7 and IL-15 generated CD19 CAR T cells is being evaluated in a clinical trial (NCT02652910).

Interestingly, CAR T cells expanded in IL-15 alone also had a $\mathrm{T}_{\mathrm{SCM}}$-like phenotype. These $\mathrm{T}_{\mathrm{SCM}}$-like cells had reduced exhaustion markers, higher antiapoptotic properties and increased proliferative capacity compared with the cells cultured with IL-2. In addition, these $\mathrm{T}_{\mathrm{SCM}}$-like cells had decreased mammalian target of rapamycin complex 1 (mTORC1) activity, and improved mitochondrial fitness. The addition of the mTORC1 inhibitor rapamycin to the CAR T cell culture with IL-2 in the absence of IL-15 exhibited a similar $\mathrm{T}_{\mathrm{SCM}}$ phenotype, suggesting that decreasing mTORC1 activity could preserve the $\mathrm{T}_{\mathrm{SCM}}$-like phenotype. ${ }^{27}$ Other $\gamma$-cytokines, such as IL-21, have also been tested in culture to generate 'fit' $\mathrm{T}_{\mathrm{SCM}}$-like cells. Clinical procedures using $\mathrm{CD} 8{ }^{+} \mathrm{CD} 62 \mathrm{~L}^{+} \mathrm{CD} 45 \mathrm{RA}{ }^{+}$ enriched naive cells cultured in the presence of IL-7, IL-21 and TWS119 demonstrated that TWS119 has a synergistic effect with IL-21 to enhance $\mathrm{T}_{\mathrm{SCM}}$ generation, through stabilization of $\beta$-catenin and induction of maximal expression of TCF1 and LEF1. These $\mathrm{T}_{\mathrm{SCM}}$-like CAR $T$ cells demonstrated enhanced metabolic fitness 
compared with the current standard CAR T cells, and mediated robust, long-lasting antitumor activity in NSG mice. ${ }^{24}$ A clinical trial (NCT01087294) has commenced to test these $\mathrm{T}_{\mathrm{SCM}}-\mathrm{CAR} \mathrm{T}$ cell products.

\section{Tissue resident $\mathrm{T}$ memory cells}

After the resolution of an immune response, $\mathrm{T}$ cells that entered into an inflamed tissue can be retained in the tissue where they become resident $T$ memory cells $\left(\mathrm{T}_{\mathrm{RM}}\right)$ cells. The function of $T_{R M}$ cells is to provide regional surveillance for reinfection, therefore $T_{R M}$ cells do not recirculate in the blood like other T cells. Phenotypically, human and murine $\mathrm{T}_{\mathrm{RM}}$ cells express similar markers which are essential for their tissue retention. These include the constitutive expression of CD69 and CD49a, which bind to extracellular matrix components (figure 1). $\mathrm{T}_{\mathrm{RM}}$ cells also lack the expression of CD62L and CCR7 that normally enable entry into lymphoid tissue.

$\mathrm{T}_{\mathrm{RM}}$ cells have been identified in almost all organs, and their expression profiles vary in different tissues, enabling their tissue-specific retention. ${ }^{28}$ In the case of $T_{R M}$ cells in epithelial tissues, integrin CD103 binds to E-cadherin and promotes $\mathrm{T}_{\mathrm{RM}}$ adhesion to epithelial cells. In human tumors of epithelial origin, including the tumors of breast, lung, ovary and bladder, patients with the greatest portion of $\mathrm{CD} 103^{+} \mathrm{CD}^{+} \mathrm{T}_{\mathrm{RM}}$-phenotype cells in their tumors have the best survival. ${ }^{28}$ This phenomenon could be explained by an enhanced cytotoxic effect of the $T_{R M}$ cells than the CD103 $\mathrm{T}^{-}$cells. ${ }^{29}$

In addition to their direct cytotoxic activity, $\mathrm{T}_{\mathrm{RM}}$ cells can produce large amounts of cytokines that can activate and attract other anti-tumor immune cells. The presence of $\mathrm{T}_{\mathrm{RM}}$ is associated with a higher density of $\mathrm{T}$ cell infiltration in lung and breast tumors. ${ }^{30}{ }^{31} \mathrm{~T}_{\mathrm{RM}}$ cells have also been demonstrated to promote tumor antigen spreading by activating cross-presenting dendritic cells (DCs) to prime and expand new cytotoxic $\mathrm{T}$ cells with different tumor-antigen specificities. This resulted in broader protection against cancers, especially from cancer cells lacking $\mathrm{T}_{\mathrm{RM}}$ targeted antigens. ${ }^{32}$ Recently, $\mathrm{T}_{\mathrm{RM}}$ cells were proposed to be a mediator in checkpoint blockade therapies. Analysis of several tumor types have shown $\mathrm{T}_{\mathrm{RM}}$ cells expressing high levels of programmed cell death protein 1 (PD1), exhibiting rapid expansion, ${ }^{33}$ cytotoxic effects $^{34}$ and expression of cytotoxicity genes following anti-PD1 treatment. $^{35}$

Due to their quick and robust immune responses at the tumor site, promoting ACT cell differentiation into $T_{R M}$ cells in vivo may be important for the long-term control of the disease. Recruitment of activated T cells into tissues depends on the cytokine/chemokine receptors and adhesion molecules expressed by $\mathrm{T}$ cells. Therefore, ACT products must express or obtain these factors in order to effectively traffic to tumors and establish residency. Additionally, strategies for reprograming the TME for optimal $\mathrm{T}_{\mathrm{RM}}$ generation is desired. To achieve this, a study used intratumoral delivery of the $\beta$-glucan curdlan, whose receptor dectin-1 is expressed by DCs and macrophages.
The $\beta$-glucan curdlan reprogramed tumor infiltrating DCs and induced $C D 8^{+} \mathrm{T}$ cells to differentiate into $\mathrm{T}_{\mathrm{RM}}$ cells which resulted in inhibited cancer progression in a humanized murine breast cancer model. ${ }^{36}$ Localized radiotherapy that has been widely used to reprogram $\mathrm{TME}^{37}$ could also be considered to enhance $\mathrm{T}_{\mathrm{RM}}$ generation. A recent study demonstrated that post irradiation, tumor infiltrating $\mathrm{T}$ cells were reprogrammed to express a similar transcriptome to that of $\mathrm{T}_{\mathrm{RM}}$ cells, which are also radioresistant. These reprogrammed $\mathrm{T}$ cells retained their motility, ability to produce interferon (IFN)- $\gamma$ and mediated antitumor responses. ${ }^{38}$ Despite the potential benefit of an ACT product with a $\mathrm{T}_{\mathrm{RM}}$-like phenotype, little has been reported on generating such cells in vitro.

\section{MIGRATION AND PENETRTION INTO TUMORS: T CELL TRAFFICKING MOLECULES}

$\mathrm{T}$ cell infiltration from the blood into the tumor is a multistep process. Activated T cells gain expression of tissue homing molecules, which include adhesion molecules and chemokine receptors. ${ }^{39}$ The first step in T cell infiltration requires the slowing of $\mathrm{T}$ cell movement by the interaction of selectin ligands on $\mathrm{T}$ cells to the selectin molecules on endothelial cells. T cells then 'roll' slowly along the blood vessel surface, which provides an opportunity to encounter chemokines produced by the tissue. Chemokine receptors on $\mathrm{T}$ cells bind to the chemokines, thereby initiating the activation of $\mathrm{T}$ cell-expressed integrins, such as lymphocyte function-associated antigen-1 (LFA-1) and very late antigen-4 (VLA-4). The binding of the activated integrins to their cognate ligands on the vessel surface mediates firm arrest of $\mathrm{T}$ cells. This is followed by transmigration through endothelial cell junctions of the blood vessels into tissues along a gradient of chemokines. Inefficient trafficking and infiltration of $\mathrm{T}$ cells into the tumor have been identified as a major hurdle for using CAR T cells in treating solid tumors. ${ }^{39}$ We show in figure 2 that three families of molecules are essential for T cell trafficking and can be exploited in the design of CAR T cells for improved trafficking.

\section{Selectins and selectin ligands}

Selectins are a family of calcium-dependent adhesion molecules and two members have been identified on endothelium. P-selectin (CD62P) is expressed by activated blood vessels and mediates weak interaction and rolling of $\mathrm{T}$ cells along the vascular endothelium. Decreased vascular P-selectin expression has been associated with cancer progression in melanoma ${ }^{40}$ and colorectal cancer. ${ }^{41}$ It has been demonstrated that in malignant primary tumors and in metastatic lesions of melanoma or colorectal cancers, P-selectin expression was nearly absent and hardly any leukocytes infiltration was detected. ${ }^{40}{ }^{41}$ P-selectin cannot be induced by inflammatory mediators (tumor necrosis factor (TNF)- $\alpha$, IL-1 $\beta$, and lipopolysaccharide (LPS)) in humans. ${ }^{42}$ 


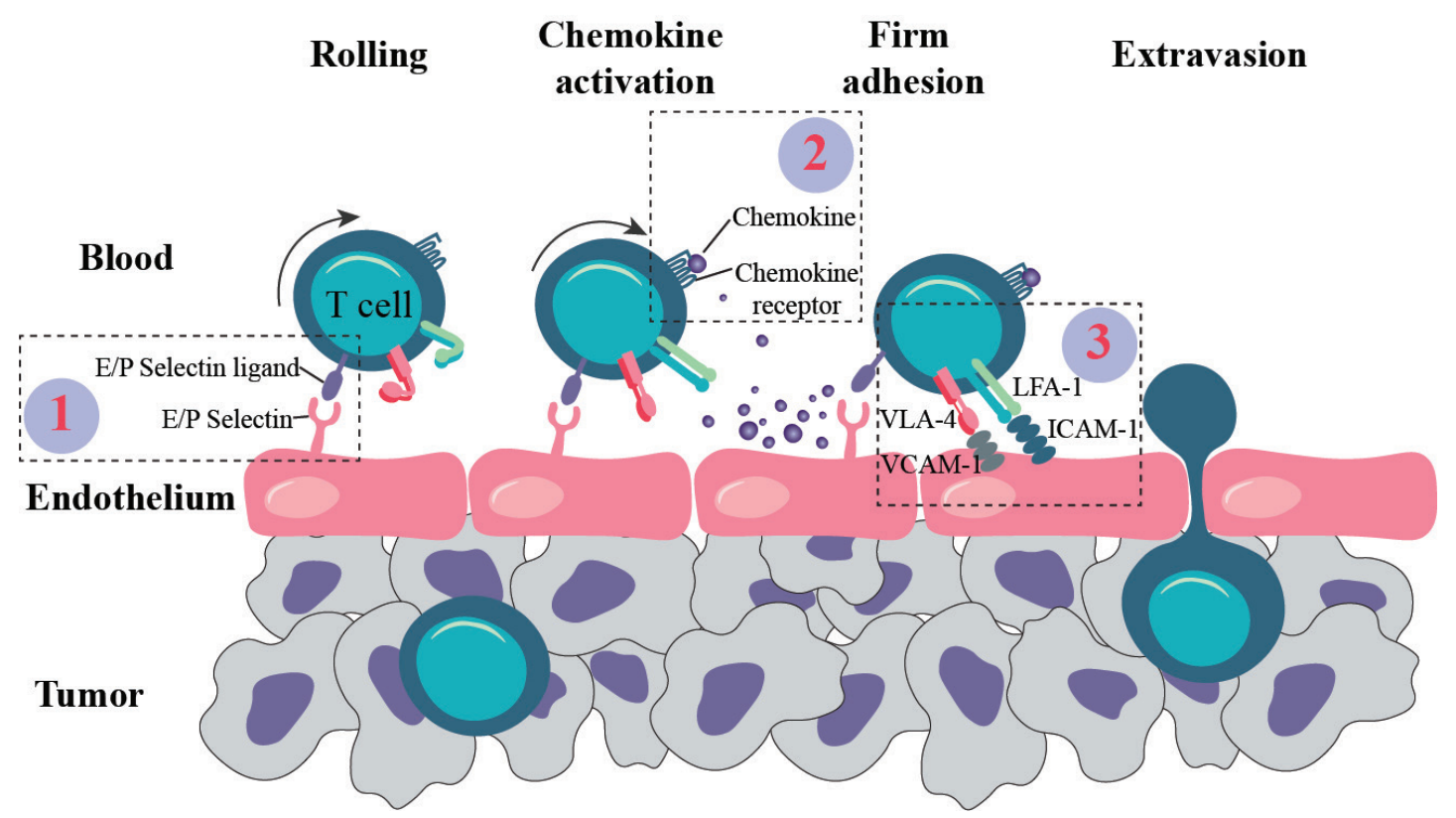

Figure 2 T cell homing events into tumor tissue. T cell infiltration into the tumor from the blood is a multistep process involving a variety of molecules such as (1) selectins and their ligands, (2) chemokines and their receptors, and (3) integrins and their ligands. Strategies manipulating these three family of molecules essential for T cell trafficking for enhanced CAR T cell infiltration into tumors are discussed in the main text. The first step in T cell infiltration requires the initiation of $\mathrm{T}$ cell rolling, or slowing of T cell movement, in the blood stream. This is facilitated by the interaction of selectin molecules on the blood vessel with their target ligands on the T cell. Next, chemokine receptors on the T cell bind to their cognate chemokines, produced by tissues or endothelium, thereby initiating the activation of integrins on the T cell. Integrins, when bound to their cognate ligands on the vessel surface, mediate firm arrest of $\mathrm{T}$ cell movement. Finally, the $\mathrm{T}$ cell is able to migrate through the cell junctions of the blood vessels into tissues, along a gradient of chemokines. CAR, chimeric antigen receptors; LFA-1, lymphocyte functionassociated antigen-1; VLA-4, very late antigen-4.

E-selectin (CD62E) is not constitutively expressed by all endothelial cells but can be induced by TNF- $\alpha$, IL-1 $\beta$, and LPS. E-selectin binding allows intimate contacts between the inflamed endothelium and T cells, slowing $\mathrm{T}$ cell rolling to much lower velocities than that of P-selectin, favoring subsequent $\mathrm{T}$ cell arrest. ${ }^{43}$

A major ligand for both $\mathrm{P}$ - and E-selectins on T cells is P-selectin glycoprotein ligand-1 (PSGL-1), whose binding to selectins requires appropriate glycosylation. Glycosyltransferases add carbohydrate moieties to PSGL-1 that form the sialylated fucosylated O-linked glycan, sialyl Lewis $x\left(\mathrm{sLe}^{\mathrm{x}}\right)$. Although PSGL-1 is expressed by most $\mathrm{T}$ cells, $\mathrm{T}_{\mathrm{N}}$ lack the proper terminal glycosylation therefore cannot bind selectins. ${ }^{44}$ Other selectin ligands on $\mathrm{T}$ cells have also been identified, including TIM1 $1{ }^{45} \mathrm{CD} 44$ and CD43. ${ }^{46}$ Blocking $\mathrm{T}$ cell binding to $\mathrm{P} / \mathrm{E}$ selectin with a monoclonal antibody exhibited poor $\mathrm{T}$ cell infiltration into tumors. ${ }^{47}$

Strategies enhancing expression of selectins and selectin ligands could be exploited for increasing engineered $\mathrm{T}$ cell trafficking to tumors. Because E-selectin expression can be induced by de novo synthesis on endothelial cells in response to inflammatory stimuli, ${ }^{48}$ methods which temporarily enhance inflammation specifically in the TME could be used prior to adoptive transfer. In fact, intratumor injection of toll-like receptor (TLR) agonists enhanced adoptively transferred $\mathrm{T}$ cell infiltration into tumors and lead to significant tumor regression in murine cancer models. ${ }^{49}$ Other strategies such as using oncolytic virus coding cytokines, and local radiotherapy that enhances local E-selectin expression can also be explored. Oncolytic virus encoding TNF- $\alpha$ and IL-2 has been shown to possess potent antitumor activity in immunocompetent Syrian hamsters. ${ }^{50} \mathrm{~A}$ clinical trial is currently in progress to study the use of this oncolytic virus in treating advanced melanoma (NCT04217473). Irradiation was found to induce the expression of E-selectin and ICAM on human endothelial cells. The induced E-selectin expression and increased adhesion of leukocytes was observed on the irradiated endothelial cells. ${ }^{51}$ Localized irradiation of tumors combined with ACT has demonstrated promise in murine tumor models, with increased $\mathrm{T}$ cell infiltration to the tumors that lead to tumor regression. ${ }^{52}$

Glycosyltransferases could be exploited to enhance the expression of selectin-binding glycoforms of PSGL-1 and CD44 on CAR T cells. In humans, there are four glycosyltransferase isoenzymes specialized to create $\operatorname{sLe}^{\mathrm{x}}$ : FT3, 5, 6 and $7 .{ }^{53}$ Mondal et a $\tilde{l}^{54}$ showed that CAR T cells expanded in standard culture conditions of CD3/CD28/IL2 had decreased expression of the $\mathrm{sLe}^{\mathrm{x}}$ moiety and reduced ability to bind E-selectin compared with the $\mathrm{T}$ cells without stimulation. The activated CAR T cells uniformly expressed high levels of Type 2 sialyllactosamines, the precursor of $\mathrm{sLe}^{\mathrm{X}}$, that can be converted to $\mathrm{sLe}^{\mathrm{X}}$ via cell surface fucosylation. After being surface fucosylated by the addition of purified FT6 enzyme, all the CAR T cells 
displayed elevated levels of sLe ${ }^{\mathrm{x}}$. As a result, CAR T cells had strikingly higher rolling and adhesion on E-selectin ${ }^{+}$ cells and 10-fold enhanced infiltration into bone marrow, where E-selectin is constitutively expressed. ${ }^{54}$

It will be interesting to investigate if other glycosyltransferases can also be used to enhance sLe ${ }^{\mathrm{X}}$ expression on CAR T cells. Cytokines such as IL-4, IL-12 and G-CSF have been reported to increase the expression levels of glycosyltransferases in T cells ${ }^{55}$ and CAR T cells secreting IL-12 have been reported to eradicate cancers. ${ }^{56}$ Various mechanisms have been linked to the enhanced efficacy, and it remains a question whether sLe ${ }^{\mathrm{x}}$ expression was increased on the IL-12-CAR T cells.

\section{Chemokines and chemokine receptors}

While a number of chemokines have been reported to be important for the migration of $\mathrm{T}$ cells into tumors, CXCR3 is one of the most important receptors in this process. CXCR3 has been found to be expressed on tumor infiltrating lymphocytes (TILs) isolated from human melanoma, colorectal and breast cancers, and a number of murine tumor models have shown the importance of CXCR3 in T cell trafficking into tumors. ${ }^{39}$ In brief, CXCR3-dependent $\mathrm{T}$ cell recruitment into tumors has been proposed to operate on a positive feedback loop. CXCL9 and CXCL10, ligands for CXCR3, are produced by immune cells, endothelial cells and cancer cells in response to IFN- $\gamma{ }^{57} \mathrm{~T}$ cells that have been recruited into inflamed tissue can locally produce IFN- $\gamma$, increasing the expression of CXCR3-ligand chemokines which can recruit additional CXCR $3^{+} \mathrm{T}$ cells-strengthening the CXCR3-T cell infiltration loop. ${ }^{58}$ CAR T cell therapies could benefit from treatments enhancing CXCR3 ligands in the TME. For example, reagents such as 5-aza-2'deoxycytidine that enhance the expression of CXCL9 and CXCL10 in the TME ${ }^{59}$ could be used to enhance CAR T cell infiltration to the TME. Similarly, reagents enhancing CXCR3 expression on CAR T cells should also be considered. Newick et $a l^{60}$ has shown that genetic inhibition of protein kinase A activity in CAR T cells increased their CXCR3 expression and improved CAR T cell trafficking to CXCL10 resulting in enhanced tumor control in tumor-bearing mice. ${ }^{60}$

There is often a mismatch of the chemokine receptors expressed by tumor reactive $\mathrm{T}$ cells and the chemokines in the tumor. Ensuring the homing phenotypes of the CAR T cells match the chemokines in the tumor can greatly enhance CAR T cell infiltration into the tumor. One approach is to transduce chemokine receptors into CAR T cells. This approach has been validated in solid tumor xenograft models. CAR $\mathrm{T}$ cells that were transduced to express CCR2b had improved infiltration into tumors in models of $\mathrm{CCL}_{2}{ }^{+}$neuroblastoma and malignant pleural mesothelioma, resulting in increased treatment efficacy. ${ }^{61}{ }^{62}$ Enforcing expression of IL-8 receptors CXCR1/2 on CAR T cells, to target IL-8 secreting tumors, increased CAR $\mathrm{T}$ cell tumor infiltration and enhanced tumor control in a murine model of glioblastoma. ${ }^{63}$
Recently, CAR T cells have been developed to produce CCL19 to recruit additional T cells and APCs to tumor tissues, and IL-7 to enhance the proliferation of survival of T cells. It has been demonstrated that enhanced interaction of APCs with CAR T cells in vivo is beneficial for the anti-tumor effect of CAR T cells. ${ }^{64-67}$ Tumors from IL-7/CCL19-CAR $T$ cell treated mice showed significantly enhanced infiltration of $\mathrm{T}$ cells and APCs, and colocalisation of CAR T cells and APCs were significantly increased in the tumors. The treatment induced eradication of all the established tumors in murine models of mastocytoma and Lewis lung carcinoma. CAR T cells in long-term surviving mice developed a $\mathrm{CD} 44^{+} \mathrm{CD} 62 \mathrm{~L}^{+}$ central memory phenotype. ${ }^{68}$ Thus, this study elegantly combined the strategies enhancing CAR $\mathrm{T}$ cell memory and trafficking and generated a superior antitumor effect.

\section{Integrins and integrin ligands}

Rolling of $\mathrm{T}$ cells along endothelium is transient unless firm adhesion mediated by integrins occurs. Integrins are cell-surface heterodimers which consist of both an alpha $(\alpha)$ and a beta $(\beta)$ chain. Multiple $\alpha$ and $\beta$ integrin subunits are expressed on T cells and the $\alpha$ and $\beta$ subunits couple to form integrins that bind their ligands on endothelium. The binding of integrins to their ligands transmits signals to $\mathrm{T}$ cells and endothelium bidirectionally. ${ }^{69}$

In resting $\mathrm{T}$ cells, the integrin LFA-1 is in a default low affinity 'bent' conformation. On encountering chemokines on endothelium, LFA-1 is converted into an extended form with an intermediate affinity (figure 2). The subsequent conformational changes promote LFA-1 transition into an active high affinity and fully extended form, supporting $\mathrm{T}$ cell arrest through binding to integrin ligands on the endothelium. ${ }^{69}$ Another important integrin is VLA-4. Similar to LFA-1, after the activation and conformational change, VLA-4 binds to its ligand vascular cell adhesion molecule-1 (VCAM-1) on blood vessels. ${ }^{69}$

Although CAR T cells have been designed to target integrin expressing cancer cells, ${ }^{70}$ to our knowledge, strategies altering CAR T cell expression of integrins for improved $\mathrm{T}$ cell infiltration are underexplored. Alternatively, treatments that induce the integrin receptor expression on tumor vessel cells can be used in combination with CAR $\mathrm{T}$ cells to improve $\mathrm{T}$ cell infiltration. It was reported that the administration of recombinant adenovirus encoding IL-12 upregulated VCAM-1 expression on tumor endothelium and mediated the recruitment of adoptively transferred $\mathrm{T}$ cells. ${ }^{71}$

\section{RESISTING LOSS OF T CELL FUNCTION: MARKERS OF T CELL EXHAUSTION}

In order to avoid causing damage to normal tissues, T cells downregulate their functions and develop a phenotype termed as exhaustion. An early study in chronic lymphocytic choriomeningitis virus (LCMV) infected mice found that some viral-specific $\mathrm{T}$ cells persisted for a long-time, 


\section{Exhausted T cell}

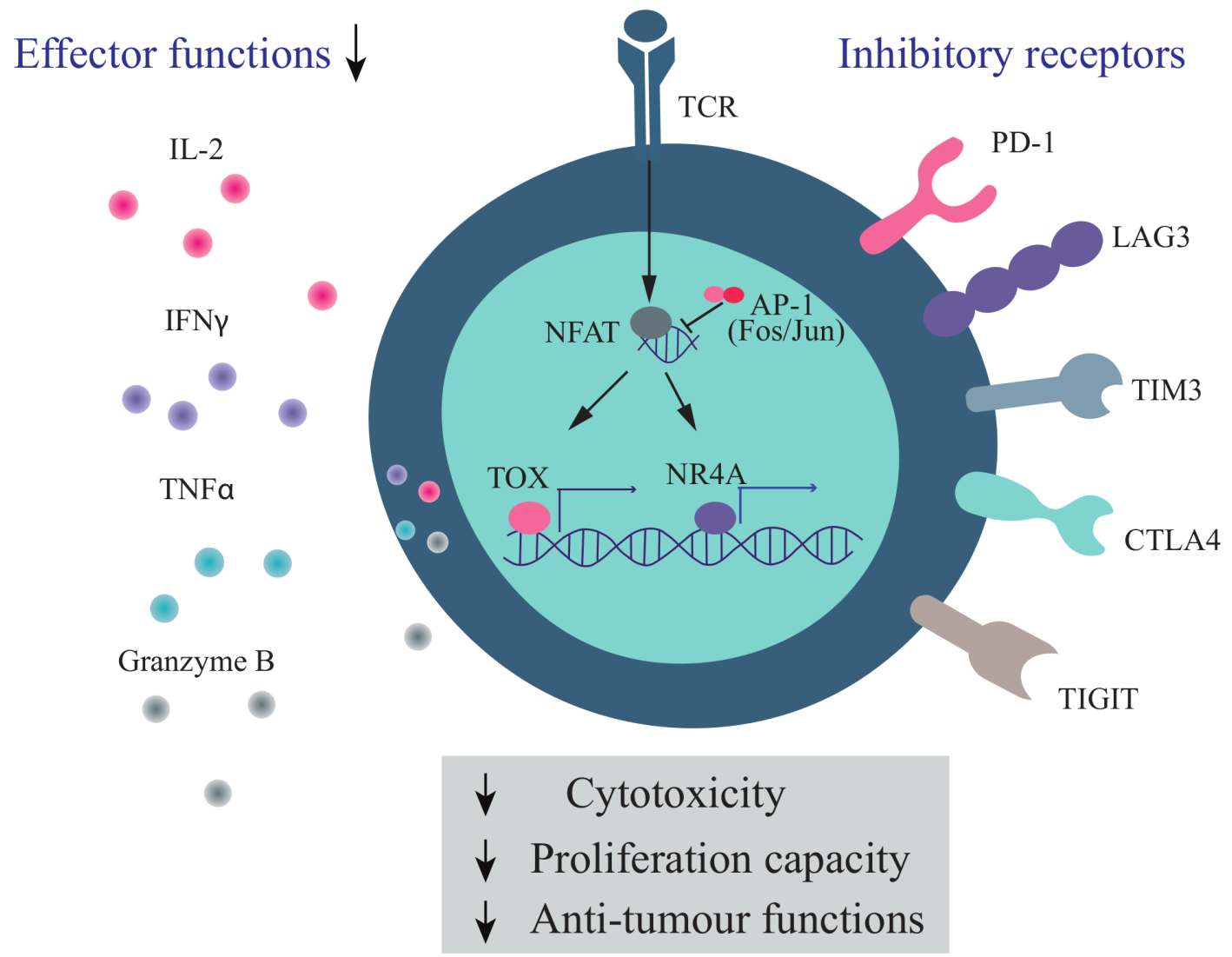

Figure 3 Markers of T cell exhaustion. T cell dysfunction occurs when there is chronic exposure to antigen, such as in the context of cancer. This loss of function is referred to as T cell exhaustion. T cell exhaustion includes the loss of IL-2 production, decreased proliferative capacity, and reduced cytotoxic abilities, including impairment in granzyme B, IFN- $\gamma$ and TNF- $\alpha$ production. Along with the loss of functionality, T cells increase the expression of inhibitory receptors such as PD1, LAG3, Tim3, CTLA4, and TIGIT. Some of the key regulators of T cell exhaustion include the transcription factors TOX and NR4A (NR4A1, NR4A2, and NR4A3). IFN- $\gamma$, interferon- $\gamma$; IL-2, interleukin 6; TNF- $\alpha$, tumor necrosis factor- $\alpha$.

proliferated in vivo, but were unable to generate an effective antiviral response. These $\mathrm{T}$ cells were engaged in continuous but ineffective actions and were likened to 'Sisyphus', the Greek king, who was tasked to perform the fruitless job of rolling a boulder up a hill only to see it roll down again. ${ }^{72}$

Exhausted T cells ( $\mathrm{T}_{\mathrm{ex}}$ cells) represent a distinct population with a unique phenotypic, epigenetic and transcriptional profiles. The ontogeny of $\mathrm{T}_{\mathrm{ex}}$ cells is still poorly understood, but the exhausted state can be induced in $\mathrm{T}$ cells at any differentiation stage and these $\mathrm{T}_{\mathrm{ex}}$ cells continue to produce exhausted progeny. Thus, exhaustion is a parallel program to $\mathrm{T}$ cell differentiation. ${ }^{73}$ The development of $\mathrm{T}_{\text {ex }}$ cells is progressive-beginning with the loss of IL-2 production, lower proliferative capacity, and reduced cytotoxic abilities. In further stages of dysfunction, $\mathrm{T}$ cells have an impairment in their ability to produce cytokines such as IFN- $\gamma$ and TNF- $\alpha .{ }^{74}$ Correlating with the progressive accumulation of functional impairments is the expression of well-defined immune checkpoint markers, which include inhibitory receptors such as PD1, LAG3, TIM3, CTLA4, and TIGIT (figure 3).
Functionally impaired $\mathrm{T}$ cells have been widely documented in solid tumors such as renal cell carcinoma, nonsmall cell lung cancer and melanoma. ${ }^{75-79}$ While difficult to dissect the development of $\mathrm{T}_{\mathrm{ex}}$ cells in humans, Schietinger $e t a l^{80}$ used a murine cancer model and demonstrated that the unresponsive $\mathrm{T}_{\mathrm{ex}}$ cells could develop at the prephase and early phase of the tumor growth, due to persistent antigen exposure. Although $\mathrm{T}_{\mathrm{ex}}$ cells in tumors are similar to those generated in chronic viral infection, they are not identical. For example, tumor $\mathrm{T}_{\mathrm{ex}}$ cells lose Eomesodermin (EOMES) expression while LMCV $\mathrm{T}_{\mathrm{ex}}$ cells express high levels of EOMES. ${ }^{80}$ Factors such as the immunosuppressive TME and the lack of co-stimulation in tumor settings may contribute to the difference.

The identification of a $\mathrm{PD} 1^{+} \mathrm{TCF} 1^{+} \mathrm{CD} 8^{+} \mathrm{T}$ cell subset presents a link between $\mathrm{T}$ cell memory and exhaustion. These cells were identified in cancers of mice and humans and have stem cell-like properties while displaying exhausted features. $\mathrm{PD} 1^{+} \mathrm{TCF} 1^{+} \mathrm{CD} 8^{+} \mathrm{T}$ cells can expand to produce terminally differentiated $\mathrm{PD}^{+}{ }^{+} \mathrm{TCF} 1^{-} \mathrm{T}$ cells while maintaining a pool of progenitor $\mathrm{PD} 1^{+} \mathrm{TCF} 1^{+} \mathrm{T}$ cells. Tumor control elicited by checkpoint 
blockade treatments is dependent on the existence of intratumoral $\mathrm{PD}^{+} \mathrm{TCF}^{+} \mathrm{CD}^{+} \mathrm{T}$ cells and argues that checkpoint blockade expands and differentiates a stem cell-like progenitor cell population, rather than reverse a terminal T cell exhaustion program. ${ }^{81}$ Interestingly, a separate study demonstrated that a memory-precursorlike PD1 ${ }^{-} \mathrm{TCF}^{+}{ }^{+} \mathrm{CD} 8^{+}$TIL subset expanded on checkpoint blockade and provided a wave of $\mathrm{T}_{\mathrm{EFF}}$ cells to sustain an effective anti-tumor response. The checkpoint blockade impacted the $\mathrm{PD}^{-}$population indirectly due to the expression of checkpoint receptors on other immune cells in the TME. ${ }^{82}$ However, evidence has shown that $\mathrm{PD}^{+} \mathrm{T}$ cells have limited potential to give rise to durable memory $\mathrm{T}$ cells, and after the cessation of the PD-L1 blockade treatment, the reinvigorated $\mathrm{T}_{\mathrm{ex}}$ cells became exhausted again. Although there was a transcriptional rewiring, $\mathrm{T}_{\text {ex }}$ cells were in a stable epigenetic state that cannot be reverted following therapy. ${ }^{83}$

The effectiveness of CAR $\mathrm{T}$ cell treatment is dependent on the degree of $\mathrm{T}$ cell exhaustion. It was demonstrated that $\mathrm{T}$ cell exhaustion in cell culture limited the antitumor efficacy of CAR T cells. A GD2-CAR T cell containing $\mathrm{CD} 3 \zeta$ and $\mathrm{CD} 28$ signaling domains showed high expression of surface inhibitory receptors such as PD1, TIM-3 and LAG3, exhaustion-associated transcription factors T-bet and Blimp-1, produced cytokines poorly in response to antigen compared with $\mathrm{CD} 19.28 \zeta \mathrm{CAR} \mathrm{T}$ cells. The GD2-CAR T cells have basal levels of $\zeta$-phosphorylation (tonic signaling) whereas CD19 CAR T cells do not. Ablating the tonic signaling (by exchanging the CAR costimulatory domain from CD28 to 4-1BB) reversed the exhaustion phenotype. Interestingly, varying degrees of exhaustion, including decreased tumor clearance in mouse models, reduced cytokine production, and increased expression of multiple inhibitory receptors, were identified in other CAR products, and 4-1BB signaling ameliorated exhaustion. ${ }^{84}$

The nuclear factor TOX is a crucial regulator for the development of $\mathrm{T}_{\mathrm{ex}}$ cells. Ectopic expression of TOX in $\mathrm{T}_{\mathrm{EFF}}$ cells induced exhaustion and deletion of TOX in $\mathrm{T}_{\mathrm{ex}}$ cells abrogated exhaustion. ${ }^{85}$ In $\mathrm{CD} 8^{+} \mathrm{T}$ cells, inhibiting the interaction of NFAT1 with AP-1 increased the exhaustion transcriptional program in the T cells and decreased their ability to control infection and tumor growth in murine models. ${ }^{86}$ In addition, NR4A and TOX also maintain the exhaustion program ${ }^{7387}$ (figure 3).

A number of strategies have been used in CAR T cells to reduce exhaustion, including knocking out exhaustionassociated genes, such as NR4A and Cbl-b. The NR4A or Cbl-b knockout CAR T cells in the tumors had surface markers similar to $\mathrm{T}_{\mathrm{EFF}}$ and increased cytokine production compared with wild type, which resulted in enhanced antitumor immunity. ${ }^{87} 88$ Rescuing AP-1 signaling could also reverse the exhausted state. Overexpression of JUN rescued CAR T cell exhaustion and greatly increased the anti-tumor efficacy of CAR T cells in multiple animal models. ${ }^{89}$ CAR T cells deficient in TOX and TOX2 showed reduced expression of inhibitory receptors and were more effective against human CD19 tumors,${ }^{90}$ demonstrating knocking out TOX and its related molecules can be a strategy to reduce an exhaustion phenotype.

Further studies are needed to optimize manufacturing conditions for CAR $\mathrm{T}$ cells to receive appropriate TCR stimulation, cytokines and other supplements. Additionally, other avenues to decrease CAR $\mathrm{T}$ cell exhaustion and increase CAR T cell fitness can be explored, such as genetic modifications of CAR T cells by knocking out/in exhaustion related molecules, as well as pairing CAR $\mathrm{T}$ cell therapy with other therapies which can reduce CAR $\mathrm{T}$ cell exhaustion.

\section{CONCLUDING REMARKS}

Key challenges facing effective CAR $\mathrm{T}$ cell therapies for solid cancers include inefficient infiltration into tumors, limited in vivo persistence and a hostile TME. Understanding intrinsic $\mathrm{T}$ cell factors and properties which occur during a natural immune response can help inform the design of a CAR T cell phenotype which can overcome these challenges.

Understanding $\mathrm{T}$ cell differentiation and the corresponding functional properties has led to new thinking around the optimal $\mathrm{T}$ cell differentiation state for ACT. Understanding the homing properties of $\mathrm{T}$ cells has allowed $\mathrm{T}$ cells engineered with receptors to increase tumor infiltration. Understanding the nuclear factors involved in T cell memory formation and exhaustion will allow for the generation of new therapeutics targeting these factors. Current research points in the direction of developing an ACT product with an early memory phenotype absent of exhaustion markers that would be an ideal phenotype for an effective treatment product.

Contributors Conception and design: DGMT, MK and CS. Write, review and revision of the manuscript: DGMT, AJO, BvS, AJH, SNM, MK and CS. Supervision: MK and CS.

Funding This work was supported by grants from the National Health and Medical Research Council (NHMRC) of Australia and the National Breast Cancer Foundation (NBCF) of Australia.

\section{Competing interests None declared.}

Patient consent for publication Not required.

Provenance and peer review Not commissioned; externally peer reviewed.

Open access This is an open access article distributed in accordance with the Creative Commons Attribution Non Commercial (CC BY-NC 4.0) license, which permits others to distribute, remix, adapt, build upon this work non-commercially, and license their derivative works on different terms, provided the original work is properly cited, appropriate credit is given, any changes made indicated, and the use is non-commercial. See http://creativecommons.org/licenses/by-nc/4.0/.

\section{ORCID iD}

Clare Y Slaney http://orcid.org/0000-0002-6986-6115

\section{REFERENCES}

1 Frigault MJ, Maus MV. State of the art in CAR T cell therapy for CD19+ B cell malignancies. J Clin Invest 2020;130:1586-94.

2 Slaney CY, Wang P, Darcy PK, et al. CARs versus BiTEs: a comparison between $\mathrm{T}$ Cell-Redirection strategies for cancer treatment. Cancer Discov 2018;8:924-934. 
3 Kershaw MH, Westwood JA, Darcy PK. Gene-Engineered T cells for cancer therapy. Nat Rev Cancer 2013;13:525-41.

4 Scarfò I, Maus MV. Current approaches to increase CAR T cell potency in solid tumors: targeting the tumor microenvironment. $J$ Immunother Cancer 2017;5:28.

5 Kurts C, Robinson BWS, Knolle PA. Cross-priming in health and disease. Nat Rev Immunol 2010;10:403-14.

6 Mueller SN, Gebhardt T, Carbone FR, et al. Memory T cell subsets, migration patterns, and tissue residence. Annu Rev Immunol 2013;31:137-61.

7 Restifo NP, Gattinoni L. Lineage relationship of effector and memory T cells. Curr Opin Immunol 2013;25:556-63.

8 Gattinoni L, Klebanoff CA, Restifo NP. Paths to stemness: building the ultimate antitumour T cell. Nat Rev Cancer 2012;12:671-84.

9 Ahmed R, Bevan MJ, Reiner SL, et al. The precursors of memory: models and controversies. Nat Rev Immunol 2009;9:662-8.

10 Fraietta JA, Lacey SF, Orlando EJ, et al. Determinants of response and resistance to CD19 chimeric antigen receptor (CAR) T cell therapy of chronic lymphocytic leukemia. Nat Med 2018;24:563-71.

11 Lécuroux C, Girault I, Urrutia A, et al. Identification of a particular HIV-specific CD8+ T-cell subset with a CD27+ CD45RO-/RA+ phenotype and memory characteristics after initiation of HAART during acute primary HIV infection. Blood 2009;113:3209-17.

12 Wherry EJ, Teichgräber V, Becker TC, et al. Lineage relationship and protective immunity of memory CD8 T cell subsets. Nat Immunol 2003;4:225-34.

13 Klebanoff CA, Gattinoni L, Torabi-Parizi P, et al. Central memory self/ tumor-reactive CD8+ T cells confer superior antitumor immunity compared with effector memory T cells. Proc Natl Acad Sci U S A 2005;102:9571-6.

14 Wang X, Naranjo A, Brown CE, et al. Phenotypic and functional attributes of lentivirus-modified CD19-specific human CD8+ central memory $\mathrm{T}$ cells manufactured at clinical scale. $\mathrm{J}$ Immunother 2012;35:689-701.

15 Wang X, Popplewell LL, Wagner JR, et al. Phase 1 studies of central memory-derived CD19 CAR T-cell therapy following autologous HSCT in patients with B-cell NHL. Blood 2016;127:2980-90.

16 Gattinoni L, Lugli E, Ji Y, et al. A human memory T cell subset with stem cell-like properties. Nat Med 2011;17:1290-7.

17 Cieri N, Camisa B, Cocchiarella F, et al. IL-7 and IL-15 instruct the generation of human memory stem T cells from naive precursors. Blood 2013;121:573-84

18 Zhang Y, Joe G, Hexner E, et al. Host-reactive CD8+ memory stem cells in graft-versus-host disease. Nat Med 2005;11:1299-305.

19 Zhou X, Yu S, Zhao D-M, et al. Differentiation and persistence of memory CD8(+) T cells depend on T cell factor 1. Immunity 2010;33:229-40.

20 Gattinoni L, Zhong X-S, Palmer DC, et al. Wnt signaling arrests effector T cell differentiation and generates CD8+ memory stem cells. Nat Med 2009;15:808-13.

21 Xu Y, Zhang M, Ramos CA, et al. Closely related T-memory stem cells correlate with in vivo expansion of CAR.CD19-T cells and are preserved by IL-7 and IL-15.. Blood 2014;123:3750-9.

22 Lugli E, Dominguez MH, Gattinoni L, et al. Superior T memory stem cell persistence supports long-lived T cell memory. J Clin Invest 2013;123:594-9.

23 Biasco L, Scala S, Basso Ricci L, et al. In vivo tracking of T cells in humans unveils decade-long survival and activity of genetically modified T memory stem cells. Sci Transl Med 2015;7:273ra13.

24 Sabatino M, Hu J, Sommariva M, et al. Generation of clinical-grade CD19-specific CAR-modified CD8+ memory stem cells for the treatment of human B-cell malignancies. Blood 2016;128:519-28.

25 Muralidharan S, Hanley PJ, Liu E, et al. Activation of Wnt signaling arrests effector differentiation in human peripheral and cord bloodderived T lymphocytes. J Immunol 2011:187:5221-32.

26 Driessens G, Zheng Y, Locke F, et al. Beta-Catenin inhibits T cell activation by selective interference with linker for activation of T cellsphospholipase C- $\gamma 1$ phosphorylation. J Immunol 2011;186:784-90.

27 Alizadeh D, Wong RA, Yang X, et al. IL15 enhances CAR-T cell antitumor activity by reducing mTORC1 activity and preserving their stem cell memory phenotype. Cancer Immunol Res 2019;7:759-72.

28 Amsen D, van Gisbergen KPJM, Hombrink P, et al. Tissue-Resident memory $T$ cells at the center of immunity to solid tumors. Nat Immunol 2018;19:538-46.

29 Murray T, Fuertes Marraco SA, Baumgaertner P, et al. Very late antigen-1 marks functional Tumor-Resident CD8 T cells and correlates with survival of melanoma patients. Front Immunol 2016;7:573.

30 Ganesan A-P, Clarke J, Wood O, et al. Tissue-Resident memory features are linked to the magnitude of cytotoxic T cell responses in human lung cancer. Nat Immunol 2017;18:940-50.
31 Savas P, Virassamy B, Ye C, et al. Single-Cell profiling of breast cancer $T$ cells reveals a tissue-resident memory subset associated with improved prognosis. Nat Med 2018;24:986-93.

32 Menares E, Gálvez-Cancino F, Cáceres-Morgado P, et al. Tissueresident memory $\mathrm{CD}^{+} \mathrm{T}$ cells amplify anti-tumor immunity by triggering antigen spreading through dendritic cells. Nat Commun 2019:10:4401.

33 Edwards J, Wilmott JS, Madore J, et al. CD103 ${ }^{+}$TumorResident CD8 ${ }^{+} \mathrm{T}$ Cells Are Associated with Improved Survival in Immunotherapy-Naïve Melanoma Patients and Expand Significantly During Anti-PD-1 Treatment. Clin Cancer Res 2018;24:3036-45.

34 Djenidi F, Adam J, Goubar A, et al. CD8+CD103+ tumor-infiltrating lymphocytes are tumor-specific tissue-resident memory $\mathrm{T}$ cells and a prognostic factor for survival in lung cancer patients. J Immunol 2015:194:3475-86.

35 Clarke J, Panwar B, Madrigal A, et al. Single-Cell transcriptomic analysis of tissue-resident memory T cells in human lung cancer. $J$ Exp Med 2019;216:2128-49.

36 Wu T-C, Xu K, Banchereau R, et al. Reprogramming tumor-infiltrating dendritic cells for CD103+ CD8+ mucosal T-cell differentiation and breast cancer rejection. Cancer Immunol Res 2014;2:487-500.

37 Oliver AJ, Darcy PK, Trapani JA, et al. Cross-Talk between tumors at anatomically distinct sites. Febs $J$ 2021;288:81-90.

38 Arina A, Beckett M, Fernandez C, et al. Tumor-reprogrammed resident $\mathrm{T}$ cells resist radiation to control tumors. Nat Commun 2019;10:3959.

39 Slaney CY, Kershaw MH, Darcy PK. Trafficking of T cells into tumors. Cancer Res 2014;74:7168-74

40 Nooijen PT, Westphal JR, Eggermont AM, et al. Endothelial Pselectin expression is reduced in advanced primary melanoma and melanoma metastasis. Am J Pathol 1998;152:679-82.

41 Peeters CFJM, Ruers TJM, Westphal JR, et al. Progressive loss of endothelial P-selectin expression with increasing malignancy in colorectal cancer. Lab Invest 2005;85:248-56.

42 Pan J, Xia L, McEver RP. Comparison of promoters for the murine and human P-selectin genes suggests species-specific and conserved mechanisms for transcriptional regulation in endothelial cells. J Biol Chem 1998;273:10058-67.

43 Borsig L. Selectins in cancer immunity. Glycobiology 2018;28:648-55.

44 Ley K, Kansas GS. Selectins in T-cell recruitment to non-lymphoid tissues and sites of inflammation. Nat Rev Immunol 2004;4:325-35.

45 Angiari S, Donnarumma T, Rossi B, et al. TIM-1 glycoprotein binds the adhesion receptor P-selectin and mediates T cell trafficking during inflammation and autoimmunity. Immunity 2014;40:542-53.

46 Fuhlbrigge RC, King SL, Sackstein R, et al. CD43 is a ligand for Eselectin on CLA+ human T cells. Blood 2006;107:1421-6.

47 Fisher DT, Chen Q, Skitzki JJ, et al. IL-6 trans-signaling licenses mouse and human tumor microvascular gateways for trafficking of cytotoxic T cells. J Clin Invest 2011;121:3846-59.

48 Bevilacqua MP, Pober JS, Mendrick DL, et al. Identification of an inducible endothelial-leukocyte adhesion molecule. Proc Natl Acad Sci U S A 1987;84:9238-42.

49 Amos SM, Pegram HJ, Westwood JA, et al. Adoptive immunotherapy combined with intratumoral TLR agonist delivery eradicates established melanoma in mice. Cancer Immunol Immunother 2011;60:671-83.

50 Havunen R, Siurala M, Sorsa S, et al. Oncolytic adenoviruses armed with tumor necrosis factor alpha and interleukin-2 enable successful adoptive cell therapy. Mol Ther Oncolytics 2017;4:77-86.

51 Hallahan D, Kuchibhotla J, Wyble C. Cell adhesion molecules mediate radiation-induced leukocyte adhesion to the vascular endothelium. Cancer Res 1996;56:5150-5.

52 Lai J-Z, Zhu Y-Y, Ruan M, et al. Local irradiation sensitized tumors to adoptive $T$ cell therapy via enhancing the Cross-Priming, homing, and cytotoxicity of antigen-specific CD8 T cells. Front Immunol 2019;10:2857.

53 Mondal N, Dykstra B, Lee J, et al. Distinct human $\alpha(1,3)-$ fucosyltransferases drive Lewis-X/sialyl Lewis-X assembly in human cells. J Biol Chem 2018;293:7300-14.

54 Mondal N, Silva M, Castano AP, et al. Glycoengineering of chimeric antigen receptor (CAR) T-cells to enforce E-selectin binding. $J$ Biol Chem 2019;294:18465-74.

55 de Vries T, Knegtel RM, Holmes EH, et al. Fucosyltransferases: structure/function studies. Glycobiology 2001;11:119r-28.

56 Pegram HJ, Lee JC, Hayman EG, et al. Tumor-Targeted T cells modified to secrete IL-12 eradicate systemic tumors without need for prior conditioning. Blood 2012;119:4133-41.

57 Tokunaga R, Zhang W, Naseem M, et al. CXCL9, CXCL10, CXCL11/ CXCR3 axis for immune activation - $\mathrm{A}$ target for novel cancer therapy. Cancer Treat Rev 2018;63:40-7. 
58 Groom JR, Luster AD. CXCR3 in T cell function. Exp Cell Res 2011;317:620-31.

59 Peng D, Kryczek I, Nagarsheth N, et al. Epigenetic silencing of TH1-type chemokines shapes tumour immunity and immunotherapy. Nature 2015;527:249-53.

60 Newick K, O'Brien S, Sun J, et al. Augmentation of CAR T-cell trafficking and antitumor efficacy by blocking protein kinase $\mathrm{A}$ localization. Cancer Immunol Res 2016;4:541-51.

61 Craddock JA, Lu A, Bear A, et al. Enhanced tumor trafficking of GD2 chimeric antigen receptor $T$ cells by expression of the chemokine receptor CCR2B. J Immunother 2010;33:780-8.

62 Moon EK, Carpenito C, Sun J, et al. Expression of a functional CCR2 receptor enhances tumor localization and tumor eradication by retargeted human T cells expressing a mesothelin-specific chimeric antibody receptor. Clin Cancer Res 2011;17:4719-30.

63 Jin L, Tao H, Karachi A, et al. CXCR1- or CXCR2-modified CAR T cells co-opt IL-8 for maximal antitumor efficacy in solid tumors. Nat Commun 2019;10:4016.

64 von Scheidt B, Wang M, Oliver AJ, et al. Enterotoxins can support CAR T cells against solid tumors. Proc Natl Acad Sci U S A 2019;116:25229-35.

65 Reinhard K, Rengstl B, Oehm P, et al. An RNA vaccine drives expansion and efficacy of claudin-CAR-T cells against solid tumors. Science 2020;367:446-53.

66 Slaney CY, von Scheidt B, Davenport AJ, et al. Dual-Specific chimeric antigen receptor $T$ cells and an indirect vaccine eradicate a variety of large solid tumors in an immunocompetent, self-antigen setting. Clin Cancer Res 2017;23:2478-90.

67 Westwood JA, Ellis S, Danne J, et al. An ultrastructural investigation of tumors undergoing regression mediated by immunotherapy. Oncotarget 2017;8:115215-29.

68 Adachi K, Kano Y, Nagai T, et al. IL-7 and CCL19 expression in CAR-T cells improves immune cell infiltration and CAR-T cell survival in the tumor. Nat Biotechnol 2018;36:346-51.

69 Bertoni A, Alabiso O, Galetto AS, et al. Integrins in T cell physiology. Int J Mol Sci 2018;19. doi:10.3390/ijms19020485. [Epub ahead of print: 06 Feb 2018].

70 Whilding LM, Halim L, Draper B, et al. CAR T-cells targeting the integrin $\alpha v \beta 6$ and co-expressing the chemokine receptor CXCR2 demonstrate enhanced homing and efficacy against several solid malignancies. Cancers 2019;11. doi:10.3390/cancers11050674. [Epub ahead of print: 1405 2019]

71 Mazzolini G, Narvaiza I, Bustos M, et al. Alpha(v)beta(3) integrinmediated adenoviral transfer of interleukin-12 at the periphery of hepatic colon cancer metastases induces VCAM-1 expression and T-cell recruitment. Mol Ther 2001;3:665-72.

72 Zajac AJ, Blattman JN, Murali-Krishna K, et al. Viral immune evasion due to persistence of activated T cells without effector function. $J$ Exp Med 1998;188:2205-13.

73 Blank CU, Haining WN, Held W, et al. Defining 'T cell exhaustion'. Nat Rev Immunol 2019;19:665-74.
74 McLane LM, Abdel-Hakeem MS, Wherry EJ. CD8 T cell exhaustion during chronic viral infection and cancer. Annu Rev Immunol 2019;37:457-95.

75 Cai M-C, Zhao X, Cao M, et al. T-Cell exhaustion interrelates with immune cytolytic activity to shape the inflamed tumor microenvironment. J Pathol 2020;251:147-59.

76 Fourcade J, Sun Z, Benallaoua M, et al. Upregulation of Tim-3 and PD-1 expression is associated with tumor antigen-specific CD8+ T cell dysfunction in melanoma patients. J Exp Med 2010;207:2175-86.

77 Li X, Wang R, Fan P, et al. A comprehensive analysis of key immune checkpoint receptors on tumor-infiltrating $T$ cells from multiple types of cancer. Front Oncol 2019;9:1066.

78 Thommen DS, Schreiner J, Müller P, et al. Progression of lung cancer is associated with increased dysfunction of $T$ cells defined by coexpression of multiple inhibitory receptors. Cancer Immunol Res 2015;3:1344-55.

79 Thompson RH, Dong H, Lohse CM, et al. PD-1 is expressed by tumor-infiltrating immune cells and is associated with poor outcome for patients with renal cell carcinoma. Clin Cancer Res 2007;13:1757-61.

80 Schietinger A, Philip M, Krisnawan VE, et al. Tumor-Specific T cell dysfunction is a dynamic antigen-driven differentiation program initiated early during tumorigenesis. Immunity 2016;45:389-401.

81 Siddiqui I, Schaeuble K, Chennupati V, et al. Intratumoral Tcf ${ }^{+}$PD$1^{+} \mathrm{CD} 8^{+} \mathrm{T}$ Cells with Stem-like Properties Promote Tumor Control in Response to Vaccination and Checkpoint Blockade Immunotherapy. Immunity 2019;50:195-211.

82 Kurtulus S, Madi A, Escobar G, et al. Checkpoint Blockade Immunotherapy Induces Dynamic Changes in $\mathrm{PD}^{-1} 1^{-} \mathrm{CD} 8^{+}$Tumor Infiltrating T Cells. Immunity 2019;50:181-94.

83 Pauken KE, Sammons MA, Odorizzi PM, et al. Epigenetic stability of exhausted T cells limits durability of reinvigoration by PD-1 blockade. Science 2016;354:1160-5.

84 Long AH, Haso WM, Shern JF, et al. 4-1BB costimulation ameliorates $T$ cell exhaustion induced by tonic signaling of chimeric antigen receptors. Nat Med 2015;21:581-90.

85 Scott AC, Dündar F, Zumbo P, et al. TOX is a critical regulator of tumour-specific T cell differentiation. Nature 2019;571:270-4

86 Martinez GJ, Pereira RM, Äijö T, et al. The transcription factor NFAT promotes exhaustion of activated $\mathrm{CD} 8^{+} \mathrm{T}$ cells. Immunity 2015;42:265-78.

87 Chen J, López-Moyado IF, Seo H, et al. NR4A transcription factors limit CAR T cell function in solid tumours. Nature 2019;567:530-4.

88 Kumar J, Kumar R, Kumar Singh A, et al. Deletion of Cbl-b inhibits $\mathrm{CD}^{+} \mathrm{T}$-cell exhaustion and promotes CAR T-cell function. $J$ Immunother Cancer 2021;9.

89 Lynn RC, Weber EW, Sotillo E, et al. C-Jun overexpression in CAR T cells induces exhaustion resistance. Nature 2019;576:293-300.

90 Seo H, Chen J, González-Avalos E, et al. TOX and TOX2 transcription factors cooperate with NR4A transcription factors to impose $\mathrm{CD} 8^{+} \mathrm{T}$ cell exhaustion. Proc Natl Acad Sci U S A 2019;116:12410-5. 